\section{Commentary: Are these times still unprecedented?}

\author{
Jonathan M. Chen, MD
}

Caesar [To the Soothsayer]: The Ides of March are come. Soothsayer: Aye, Caesar, but not gone.

-William Shakespeare

(Julius Caesar, 3.1.12) ${ }^{1}$

One of the greatest challenges to global pandemic control may be the mitigation of coronavirus disease 2019 (COVID-19)-precautions fatigue. Worldwide, we now appear to be watching the consequences of progressive laxity in mask adherence, social distancing, and self-quarantine (not to mention media falsehoods). While indeed infection prevalence related to this could reflect correlation and not causation, most would agree that the Ides of March are far from gone-and daily reports of recent lockdowns across the globe reinforce that observation. In light of this, it surely behooves us to garner what conclusions can be drawn from the myriad ways in which the "first wave" of the pandemic were managed to better understand how we might oversee subsequent ones; in this issue of the Journal, the report from a consortium of congenital hospitals throughout China details their initial experience. ${ }^{2}$

Most reports over the past year have demonstrated fairly similar tactics among congenital centers internationally, namely restriction to urgent and emergent cases, limitation in visitation, enhanced use of personal protective equipment by staff, and increasing reliance on telemedicine. ${ }^{2-4}$ Those of us in the United States look admiringly at this study, which moreover depicts broad governmental restriction in travel, strict adherence to a 14-day preoperative quarantine, and widespread use of nucleic acid testing, much as we view the austere restrictions enacted in New Zealand and their low disease incidence: impressive but likely unattainable here. ${ }^{2}$

\footnotetext{
From Cardiothoracic Surgery, Children's Hospital of Philadelphia, Philadelphia, Pa. Disclosures: The author reported no conflicts of interest.

The Journal policy requires editors and reviewers to disclose conflicts of interest and to decline handling or reviewing manuscripts for which they may have a conflict of interest. The editors and reviewers of this article have no conflicts of interest.

Received for publication Nov 18, 2020; revisions received Nov 18, 2020; accepted for publication Nov 19, 2020; available ahead of print Nov 28, 2020

Address for reprints: Jonathan M. Chen, MD, Cardiothoracic Surgery, Children's Hospital of Philadelphia, 3401 Civic Center Blvd, Suite 8574, Philadelphia, PA 19104 (E-mail: chenj14@email.chop.edu).

J Thorac Cardiovasc Surg 2021;161:1615-6

$0022-5223 / \$ 36.00$

Copyright (C) 2020 by The American Association for Thoracic Surgery

https://doi.org/10.1016/j.jtcvs.2020.11.088
}

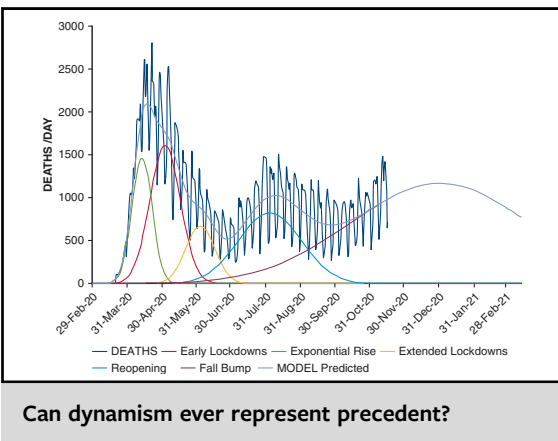

CENTRAL MESSAGE

As we face the possibility of subsequent waves of pandemia, it is of paramount importance to learn from the past.

Interestingly, despite variability in pandemic "contingency methodology," most have also reported similar findingsreduced overall surgical volume, a change in case mix toward newborn and complex disease, and thankfully a low rate of "true" severe COVID-19 disease either in congenital heart patients or transmitted to or from their health care workers. All have been limited in the ability to estimate the unintended consequence of delay in less-prioritized semielective cases that could impact perioperative outcomes, and although one might speculate that fear of major medical centersmixed with challenging logistics of travel bans and preoperative quarantine - might presage outpatient mortality, this is equally unknown.

Perhaps what this heterogeneity of management that results in homogeneity of outcome reflects is a central limitation in our understanding of COVID disease itself. Indeed, the most fundamental question remains elusive: what is the actual risk of undergoing different kinds of cardiac surgery in the setting of symptomatic disease or asymptomatic carriage? Moreover, whether the clinical disease itself in its secondary and tertiary reprises will represent the same risk, with or without a vaccine strategy, likely will only be clarified through empiricism.

All of which brings the existential question to bear: at what point do "unprecedented times" exist long enough to become established precedent? Reports such as this from Shi and colleagues help us as a community to refine what essentially must become universal precautions, understanding that it is up to individual programs to determine which aspects are actually practical within their domains. Let's just hope the Ides of March only come once a year. 


\section{References}

1. Shakespeare W. The Tragedy of Julius Caesar. New Haven, CT: Yale University Press; 1919.

2. Shi G, Huang J, Pi M, Chen X, Li X, Ding Y, et al. Impact of early Coronavirus Disease 2019 pandemic on pediatric cardiac surgery in China. J Thorac Cardiovasc Surg. 2021;161:1605-14.e4.
3. George I, Salna M, Kobsa S, Deroo S, Kriegel J, Blitzer D, et al. The rapid transformation of cardiac surgery practice in the coronavirus disease 2019 (COVID-19) pandemic: insights and clinical strategies from a center at the epicenter. J Thorac Cardiovasc Surg. 2020;160:937-47.

4. Stephens EH, Dearani JA, Guleserian KJ, Overman DM, Tweddell JS, Backer CL, et al. COVID-19: crisis management in congenital heart surgery. J Thorac Cardiovasc Surg. 2020;160:522-8.
See Article page 1605 .

\section{Commentary: Lights and shadows of pediatric cardiac surgery in China during the coronavirus disease 2019 pandemic}

\author{
Giovanni Battista Luciani, MD
}

Shi and colleagues ${ }^{1}$ describe the influence of early coronavirus disease 2019 (COVID-19) pandemic on pediatric cardiac surgery activity in China. The authors write on behalf of a consortium, gathering 13 of the largest pediatric cardiac units in the country, including the Children's Hospital in Wuhan, where the global pandemic originated. ${ }^{2}$ The report presents useful information, given the amount and quality of surgical activity reported during the lockdown period in China (January 23-April 8, 2020), and some controversial aspects. To assess the influence of the pandemic, the authors compare number and type of procedures during a similar time interval during the 2 preceding years. Quite expectedly, a $75 \%$ decrease in activity was observed, with a shift, although less impressive than expected, toward emergency procedures and elective interventions in symptomatic patients. These changes did not result in increased hospital mortality, attesting to the standard of care reached in Chinese cardiac units. The authors correlate these findings with a decrease in migration of patients and families. An

From the Division of Cardiac Surgery, Department of Surgery, Dentistry, Pediatrics, and Obstetrics/Gynecology, University of Verona, Verona, Italy.

Disclosures: The author reported no conflicts of interest.

The Journal policy requires editors and reviewers to disclose conflicts of interest and to decline handling or reviewing manuscripts for which they may have a conflict of interest. The editors and reviewers of this article have no conflicts of interest.

Received for publication Nov 18, 2020; revisions received Nov 18, 2020; accepted for publication Nov 19, 2020; available ahead of print Nov 28, 2020.

Address for reprints: Giovanni Battista Luciani, MD, Division of Cardiac Surgery, Department of Surgery, Dentistry, Pediatrics, and Obstetrics/Gynecology, University of Verona, O. C. M. Piazzale Stefani 1, Verona 37126 Italy (E-mail: giovanni. luciani@univr.it).

J Thorac Cardiovasc Surg 2021;161:1616-7

$0022-5223 / \$ 36.00$

Copyright (c) 2020 by The American Association for Thoracic Surgery

https://doi.org/10.1016/j.jtcvs.2020.11.089
Check for updates

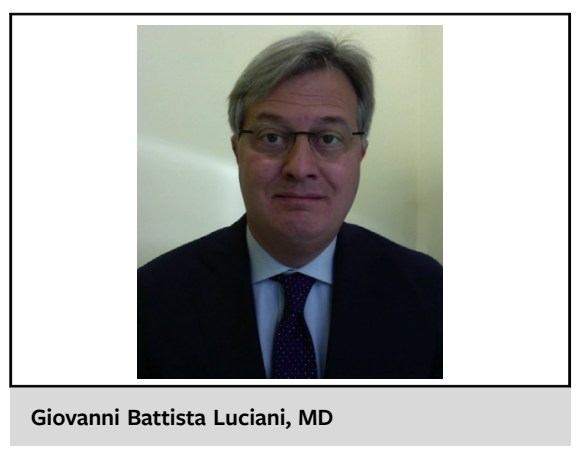

CENTRAL MESSAGE

Pediatric cardiac surgery during

the COVID-19 pandemic wit-

nessed increased case

complexity without affecting

outcomes. Routine patient and

family testing is mandatory to

establish sustainability of cardiac

programs.

innovative strategy to provide for patient follow-up despite the limited mobility of patients is also proposed. In fact, implementation of Internet and/or telephone follow-up in up to one-fourth of patients is shown not to result in increased late mortality or hospital readmission. Because a trend toward decrease in COVID-19 cases has not been witnessed yet in many countries worldwide and a second wave is humbling Europe again, safety and applicability of telemedicine to pediatric cardiac surgical patients is a precious piece of information. The report by Shi and colleagues ${ }^{1}$ presents similarities when compared with the almost-contemporary experience with pediatric cardiac surgery in Italy. But there are some striking differences. ${ }^{3}$ Amongst the Western countries, Italy was the first and hardest hit by the early phase of the COVID-19 pandemic, both in terms of number of cases 